\title{
The Use of Garcinia Extract (Hydroxycitric Acid) as a Weight loss Supplement: A Systematic Review and Meta-Analysis of Randomised Clinical Trials
}

\author{
Igho Onakpoya, Shao Kang Hung, Rachel Perry, Barbara Wider, and Edzard Ernst \\ Peninsula Medical School, University of Exeter, Devon EX2 4NT, UK \\ Correspondence should be addressed to Igho Onakpoya, igho.onakpoya@pcmd.ac.uk
}

Received 13 May 2010; Revised 13 July 2010; Accepted 22 October 2010

Academic Editor: S. B. Heymsfield

Copyright (C) 2011 Igho Onakpoya et al. This is an open access article distributed under the Creative Commons Attribution License, which permits unrestricted use, distribution, and reproduction in any medium, provided the original work is properly cited.

The aim of this systematic review is to examine the efficacy of Garcinia extract, hydroxycitric acid (HCA) as a weight reduction agent, using data from randomised clinical trials (RCTs). Electronic and nonelectronic searches were conducted to identify relevant articles, with no restrictions in language or time. Two independent reviewers extracted the data and assessed the methodological quality of included studies. Twenty-three eligible trials were identified and twelve were included. Nine trials provided data suitable for statistical pooling. The meta-analysis revealed a small, statistically significant difference in weight loss favouring HCA over placebo (MD: $-0.88 \mathrm{~kg}$; 95\% CI: $-1.75,-0.00$ ). Gastrointestinal adverse events were twice as common in the HCA group compared with placebo in one included study. It is concluded that the RCTs suggest that Garcinia extracts/HCA can cause shortterm weight loss. The magnitude of the effect is small, and the clinical relevance is uncertain. Future trials should be more rigorous and better reported.

\section{Introduction}

The prevalence of overweight and obesity has increased over the last decade [1], and current measures have not been able to stem the tide. A wide variety of weight management strategies are presently available, and some involve the use of dietary supplements marketed as slimming aids. One such slimming aid is Garcinia extract, (-)-hydroxycitric acid (HCA).

$\mathrm{HCA}$ is a derivative of citric acid and can be found in plant species native to South Asia such as Garcinia cambogia, Garcinia indica, and Garcinia atroviridis [2]. HCA is usually marketed as a weight loss supplement either alone or in combination with other supplements $[2,3]$. Some authors have suggested that HCA causes weight loss by competitively inhibiting the enzyme adenosine triphosphatase-citrate-lyase [3-6]. HCA has also been reported to increase the release or availability of serotonin in the brain, thereby leading to appetite suppression [7]. Other postulated weight loss mechanisms include inhibition of pancreatic alpha amylase and intestinal alpha glucosidase, thereby leading to a reduction in carbohydrate metabolism [8].

Animal studies have suggested that HCA causes weight loss $[3,9]$, and human trials involving the use of HCA as a weight loss supplement have been carried out [3].

The primary objective of this systematic review was to examine the efficacy of HCA in reducing body weight in humans, using data from randomised clinical trials.

\section{Methods}

Electronic searches of the literature were conducted in the following databases: Medline, Embase, The Cochrane Library, Amed, and Cinahl. The search terms used included dietary supplements, antiobesity agents, body weight, hydroxycitrate, garcinia, and derivatives of these. Each database was searched from inception until March, 2010. We also searched the Internet for relevant conference proceedings and hand searched relevant medical journals, and our own files. The bibliographies of all located articles were also searched. 


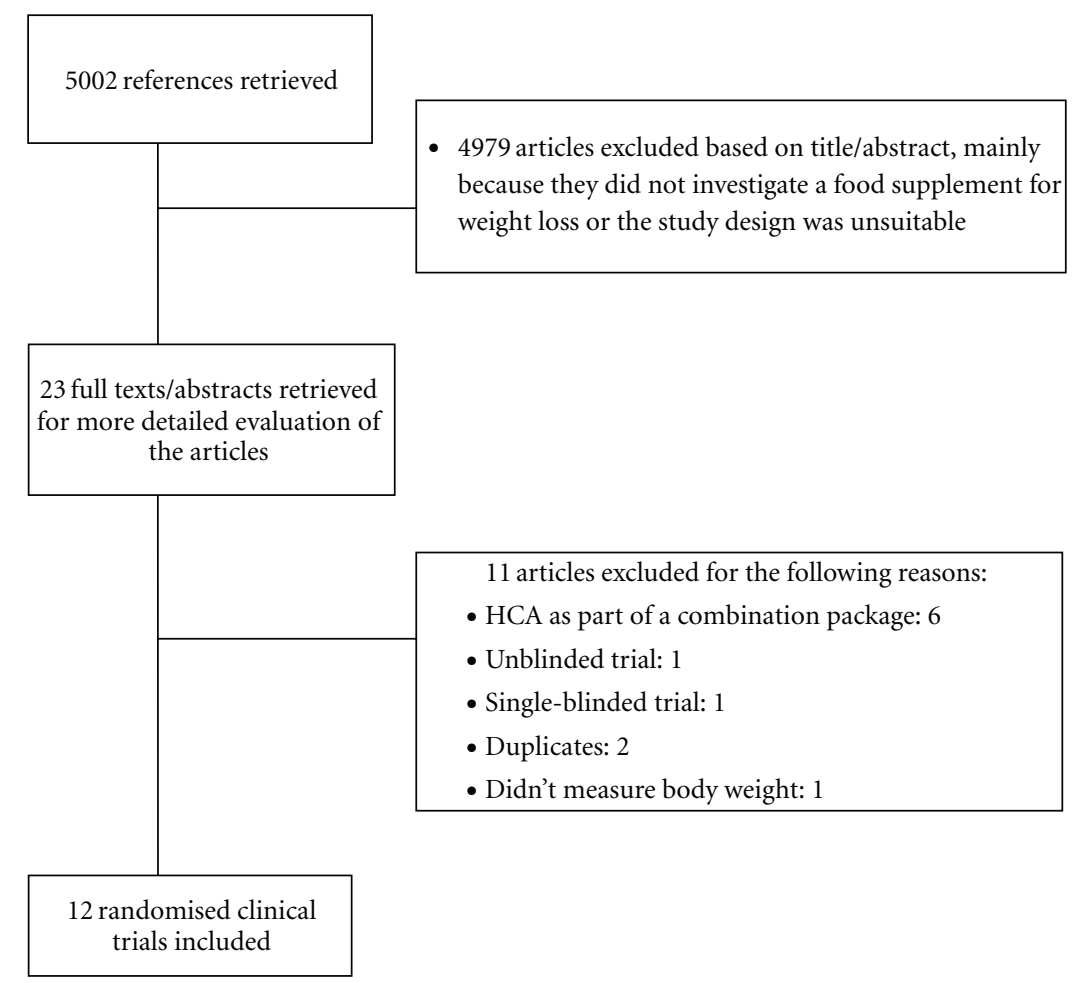

FIGURE 1: Flow chart showing the process for the inclusion of randomised controlled trials.

Only randomised, double-blind, placebo-controlled studies were included in this paper. To be considered for inclusion, studies had to test the efficacy of oral HCA or any of its salts for weight reduction in obese or overweight humans. Included studies also had to report body weight as an outcome. No age, time, or language restrictions were imposed for inclusion of studies. Studies which involved the use of HCA as part of a combination treatment (dietary interventions containing other supplements in addition to HCA), or not involving obese or overweight subjects based on body mass index (BMI) values, were excluded from this paper.

Two independent reviewers assessed the eligibility of studies to be included in the paper. Data were extracted systematically by two independent reviewers according to the patient characteristics, interventions, and results. The methodological quality of all included studies was assessed by the use of a quality assessment checklist adapted from the Consolidated Standard of Reporting Trials (CONSORT) guidelines $[10,11]$. In addition, the Jadad score [12] was also used to assess the quality of included studies. Disagreements were resolved through discussion with the other authors.

Data are presented as means with standard deviations. Mean changes in body weight were used as common endpoints to assess the differences between HCA and placebo groups. Using the standard meta-analysis software [13], we calculated mean differences (MDs) and 95\% confidence intervals (CIs). Studies included in the meta-analysis were weighted by SD (a proxy for study size). If a trial had 3 arms, only the HCA and placebo arms were included in the meta-analysis. The $I^{2}$ statistic was used to assess for statistical heterogeneity amongst studies. A funnel plot was used to test for publication bias.

\section{Results}

Our searches produced 5002 "hits" of which 23 potentially relevant articles were identified (Figure 1). Six trials were excluded because they involved the use of HCA in combination with other therapies [7, 14-18]. One trial was excluded because it was not blinded [19], and another because it was single blinded [20]. Two articles were excluded because they were duplicates. One of these articles [21] was the same trial published in another journal which had been earlier excluded, while the other article [22] was a report of two individual trials which were included in this systematic review. One trial was excluded because the investigators did not measure weight as an outcome [23]. Thus 12 randomised clinical trials (RCTs) including a total of 706 participants met our inclusion criteria, and were included in this systematic review [2, 4-6, 24-31]. Their key details are summarized in Tables 1, 2, and 3 .

All of the studies had one or more methodological weaknesses (Table 1). None of the included studies reported on how double blinding was carried out, and all studies were also unclear about how the allocation was concealed. The randomization procedure was clear in only a third of included studies $[4,6,25,29]$.

Three RCTs $[4,28,31]$ did not provide actual values to enable statistical pooling (Table 3 ). One of these RCTs 


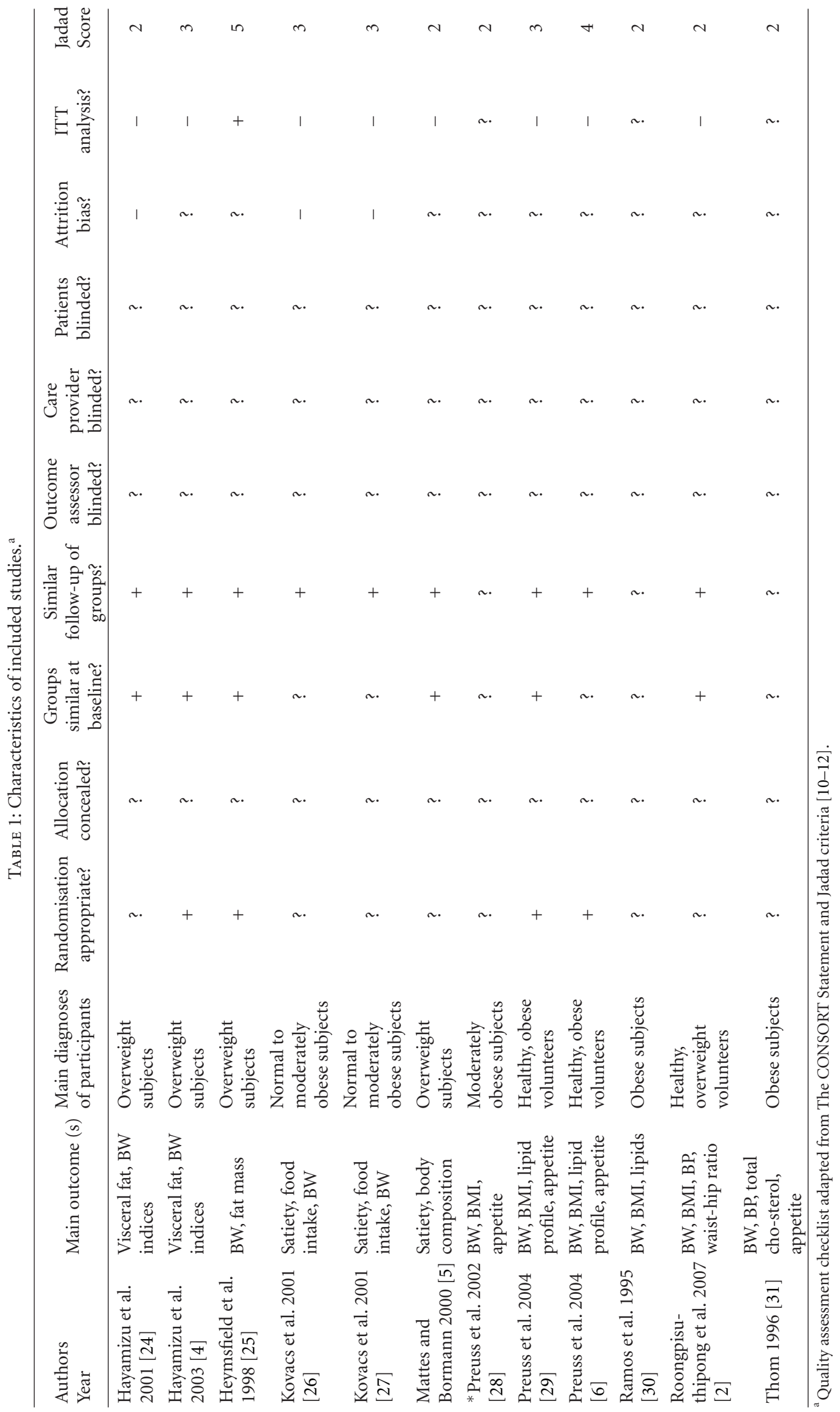




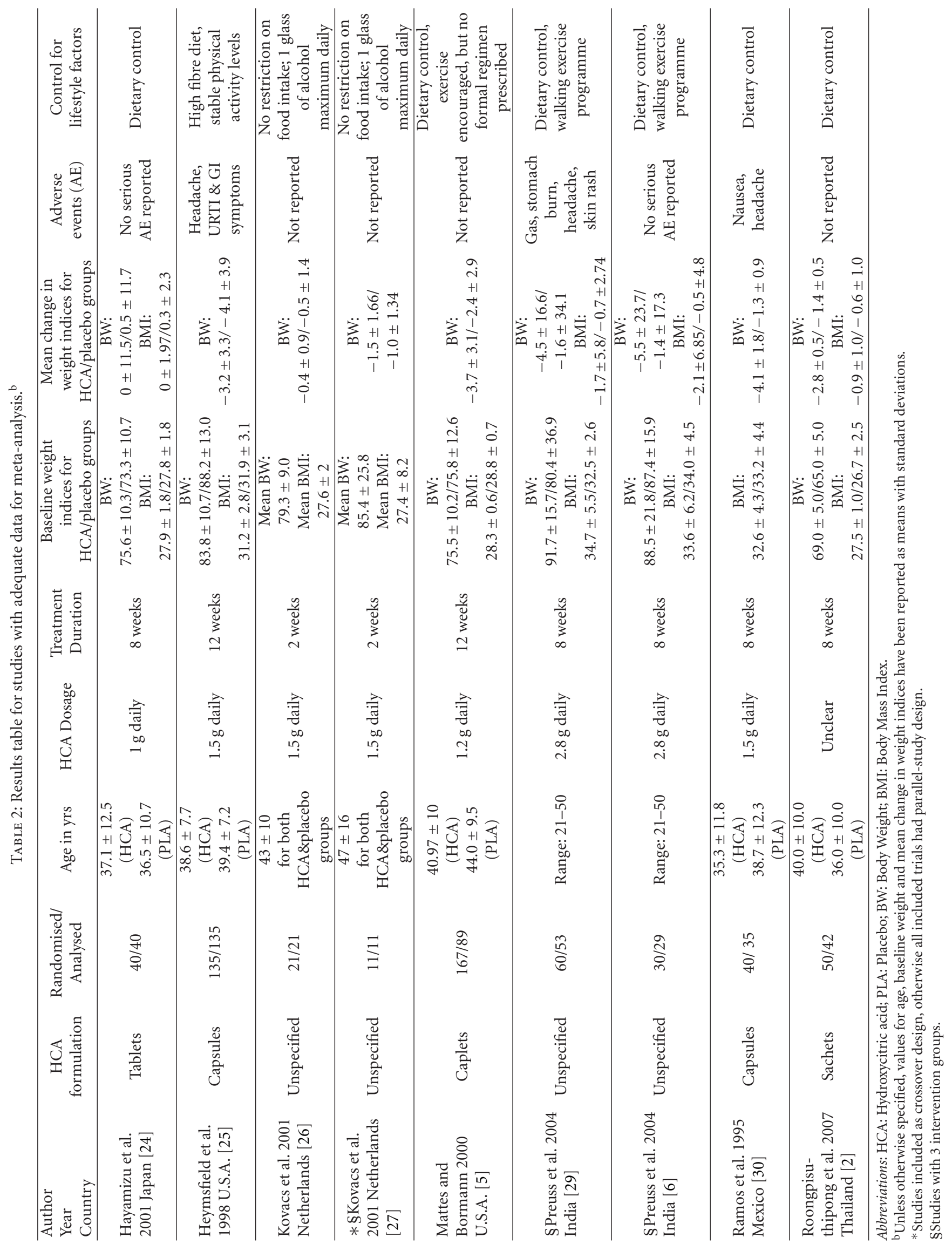


TABLE 3: Results of included studies without suitable data for meta-analysis. ${ }^{\rho}$

\begin{tabular}{|c|c|c|c|c|c|c|c|c|c|}
\hline $\begin{array}{l}\text { Author } \\
\text { Year } \\
\text { Country }\end{array}$ & $\begin{array}{c}\text { HCA } \\
\text { formulation }\end{array}$ & $\begin{array}{c}\text { Randomised/ } \\
\text { Analysed }\end{array}$ & Age in yrs & $\begin{array}{c}\text { HCA } \\
\text { Dosage }\end{array}$ & $\begin{array}{l}\text { Treatment } \\
\text { Duration }\end{array}$ & $\begin{array}{l}\text { Baseline weight } \\
\text { indices for } \\
\text { HCA/placebo } \\
\text { groups }\end{array}$ & Main Results & $\begin{array}{l}\text { Adverse } \\
\text { events } \\
(\mathrm{AE})\end{array}$ & $\begin{array}{l}\text { Control } \\
\text { for lifestyle } \\
\text { factors }\end{array}$ \\
\hline $\begin{array}{l}\text { Hayamizu } \\
\text { et al. } 2003 \\
\text { Japan [4] }\end{array}$ & Tablets & $44 / 39$ & $\begin{array}{l}43.7 \pm 11.9 \\
(\mathrm{HCA}) \\
45.2 \pm 13.0 \\
(\text { PLA })\end{array}$ & $1 \mathrm{~g}$ daily & 12 weeks & $\begin{array}{c}\text { BW: } \\
75.1 \pm 12.3 / \\
75.9 \pm 11.5 \\
\text { BMI: } \\
28.9 \pm 4.7 / \\
28.5 \pm 4.6\end{array}$ & $\begin{array}{l}\text { No significant } \\
\text { differences in } \\
\text { BMI or body } \\
\text { weight at week } 12\end{array}$ & $\begin{array}{l}\text { Common } \\
\text { cold, } \\
\text { toothache, } \\
\text { diarrhea }\end{array}$ & $\begin{array}{l}\text { Dietary } \\
\text { control }\end{array}$ \\
\hline $\begin{array}{l}\text { Preuss et al. } \\
2002 \\
\text { (abstract) } \\
\text { India [28] }\end{array}$ & Unspecified & 48/unclear & $\begin{array}{l}\text { Not } \\
\text { reported }\end{array}$ & $2.8 \mathrm{~g}$ daily & 8 weeks & Not reported & $\begin{array}{l}4.8 \% \text { loss in body } \\
\text { weight, and } 6.8 \% \\
\text { decrease in BMI } \\
\text { for HCA group }\end{array}$ & $\begin{array}{l}\text { Not } \\
\text { reported }\end{array}$ & $\begin{array}{l}\text { Diet } \\
\text { control, } \\
\text { exercise }\end{array}$ \\
\hline $\begin{array}{l}\text { Thom } 1996 \\
\text { (abstract) } \\
\text { Norway } \\
{[31]}\end{array}$ & Capsule & 60/unclear & $\begin{array}{l}\text { Not } \\
\text { reported }\end{array}$ & $1.32 \mathrm{~g}$ daily & 8 weeks & Not reported & $\begin{array}{l}\text { Significant } \\
\text { decrease in body } \\
\text { weight in HCA } \\
\text { group compared } \\
\text { with placebo } \\
(P<.001)\end{array}$ & $\begin{array}{l}\text { Stomach } \\
\text { ache }\end{array}$ & $\begin{array}{l}\text { Low fat } \\
\text { diet, } \\
\text { exercise }\end{array}$ \\
\hline
\end{tabular}

Abbreviations: HCA: Hydroxycitric acid; PLA: Placebo; BW: Body Weight; BMI: Body Mass Index.

${ }^{\rho}$ Unless otherwise stated, all trials are parallel-study designs.

reported a nonsignificant difference in BMI or body weight between groups [4], another reported a significant difference $(P<.001)$ in the HCA group compared with placebo [31]. The third RCT [28] reported a decrease in body weight and (BMI) from baseline for the HCA group, without providing results of intergroup differences.

A forest plot (random effect model) for studies with data suitable for statistical pooling is shown in Figure 2. The meta-analysis reveals a statistically significant difference in body weight between the HCA and placebo groups. The average effect size was, however, small (MD: $-0.88 \mathrm{~kg}$; $95 \%$ CI: $-1.75,-0.00)$, with a $P$ value of .05 . This translates to about $1 \%$ in body weight loss in HCA group compared with placebo. The $I^{2}$ statistic suggests that there was considerable heterogeneity amongst the trials, the duration of treatment, and the dosages of HCA used in the different trials varied widely. A funnel plot of mean difference plotted against trial sample size (Figure 3) indicated that most of the studies (which had small sample sizes) were distributed around the mean difference of all the trials.

Sensitivity analyses were performed to test the robustness of the overall analysis. The first included 7 trials $[2,5,6$, $24,25,29,30]$ with parallel-group design, excluding two studies which were crossover $[26,27]$. Meta-analysis of these trials revealed MD of $-1.22 \mathrm{~kg}$ (95\% CI: $-2.29,-0.14)$. Heterogeneity was substantial. A second meta-analysis for studies with parallel group designs and dosage ranges of HCA between 1 and $1.5 \mathrm{~g}$ per day $[5,24,25,30]$ did not reveal a significant difference between HCA and placebo; heterogeneity was also substantial in this analysis. A third meta-analysis excluding three studies with outlying data for MD $[6,29,30]$ did not reveal a significant difference in weight loss between HCA and placebo, but heterogeneity was considerable. A further meta-analysis of the two trials with good methodological quality $[6,25]$ revealed a nonsignificant difference in weight loss (MD: $0.88 \mathrm{~kg} ; 95 \%$ CI: $-0.33,2.10)$ between HCA and placebo, with $I^{2}$ value of 0 , suggesting that heterogeneity might not be important. Finally, a meta-analysis of the change in BMI for four studies $[6,24,29,31]$ did not reveal any significant difference between HCA and placebo (MD: $-0.34 \mathrm{~kg} ; 95 \% \mathrm{CI}:-0.88$, $0.20)$, with $I^{2}$ value of 0 .

One study [2] reported a significant decrease in fat mass in the HCA group compared with placebo $(P<.05)$, while two studies $[4,24]$ reported a significant decrease in visceral, subcutaneous, and total fat areas in the HCA group compared with placebo $(P<.001)$. In contrast two other studies $[5,25]$ found no significant difference in body fat loss between HCA and placebo.

Adverse events reported in the RCTs included headache, skin rash, common cold, and gastrointestinal (GI) symptoms. In most of the studies, there were no major differences in adverse events between the HCA and placebo groups. However, in one trial, GI adverse events were twice as frequent in the HCA group compared with the placebo group [25]. In total, there were 88 drop outs. A further 45 participants were reported to have been excluded from the analysis in one trial [5] because they either took a mixture of HCA and placebo (28), or were males (17).

\section{Discussion}

The objective of this systematic review was to assess the efficacy and effectiveness of HCA as a weight reduction agent. The overall meta-analysis revealed a small difference in change in body weight between the HCA and placebo groups. The effect is of borderline statistical significance and is no longer significant on the basis of a sensitivity analysis 


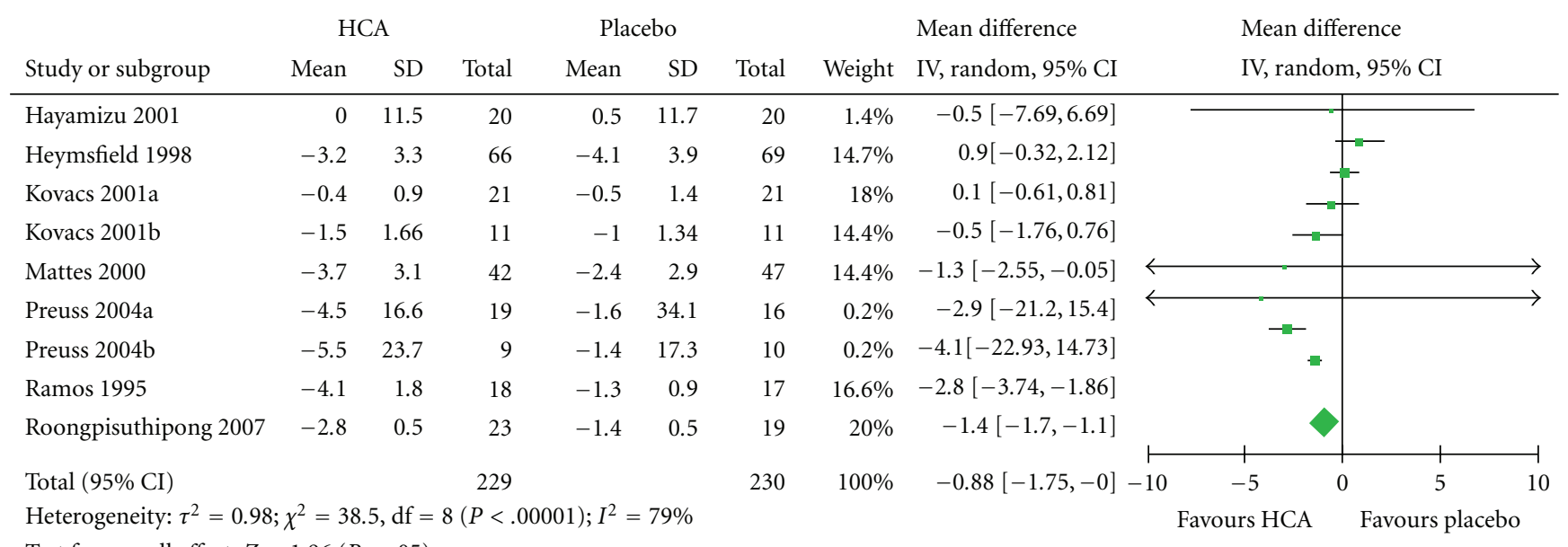

FIGURE 2: Forest plot of comparison showing the effect of hydroxycitrate on body weight. The vertical line represents no difference in weight loss between HCA and placebo.

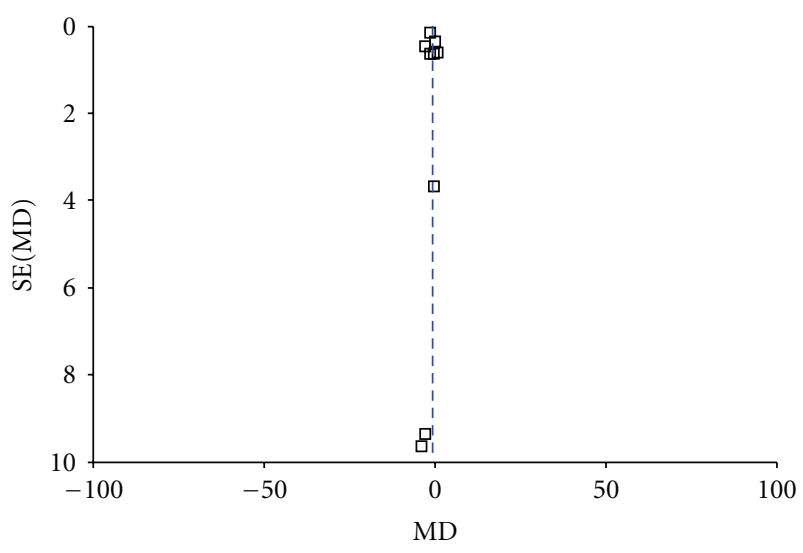

Figure 3: Funnel plot of the mean difference in body weight reduction trials of HCA, plotted against sample size. The vertical line depicts the weighted mean difference of all trials.

of rigorous RCTs. Arguably the overall effect size is also too small to be of clinical relevance. The overall meta-analytic result corroborates the findings from one of the studies without suitable data for statistical pooling [31], but is at variance with another study [4].

The overall result should be interpreted with caution. The pooled data from some of the studies were adjusted values. Three studies with small sample sizes $[6,29,30]$ seemed to have influenced the overall meta-analytic result in favour of HCA over placebo. If these three trials are excluded, the meta-analysis result is no longer significant. The largest and most rigorous RCT [25] found no significant difference in weight loss between HCA and placebo.

The result of our systematic review corroborates the findings from a previous systematic review of weight loss supplements, which reported that the weight reducing effects of most dietary supplements is not convincing [32]. HCA is a commonly marketed as a complementary weight loss supplement. The meta-analysis from this systematic review suggests that HCA is not as effective as conventional weight loss pills, for example, orlistat. In a meta-analysis report of 16 studies including over 10000 participants [33], overweight and obese patients taking orlistat had a clinically significant reduction in body weight compared to placebo (MD: $2.9 \mathrm{~kg}$; 95\% CI: 2.5, 3.2). Participants taking orlistat achieved a 5\% and $10 \%$ weight loss compared to placebo in the results from pooled data. This contrasts quite sharply with the results from the meta-analysis of HCA clinical trials.

All of the studies included in this review had methodological issues, which are likely to have affected the outcomes in these trials. This is supported by the $I^{2}$ values from the overall meta-analysis result which suggested substantial heterogeneity. Most of the studies included in this systematic review had small sample sizes. Only one included study [25] reported that they performed a power calculation. Larger study sizes with a priori sample size calculation will help eliminate a type II error (i.e., failure to reject the null hypothesis when it should have been rejected). Only one study [25] performed an intention to treat (ITT) analysis, while all the participants in three other studies [24, 26, 27] were reported to have completed the trial. The failure of about $66 \%$ of the included studies to report ITT analyses casts a doubt as to the validity of their results. In several of the RCTs, drop-outs/attrition was unclear. In one study [5], participants were excluded due to mixed-pill ingestion (an error in coding of pill bottles resulted in some participants receiving a mixture of HCA and placebo). Male participants were also excluded from the analysis of this RCT because they were too few in number compared with females in the trial. It was also unclear to which intervention group the excluded participants belonged to in this study.

The dosage of HCA, and the duration of study also varied amongst the RCTs. The dosage of HCA used ranged from $1 \mathrm{~g}$ to $2.8 \mathrm{~g}$ daily. The optimal dose of HCA is currently unknown. Two included studies which differed widely in results $[25,29]$ also differed widely in dosage of HCA. 
Dose effect of HCA on body weight

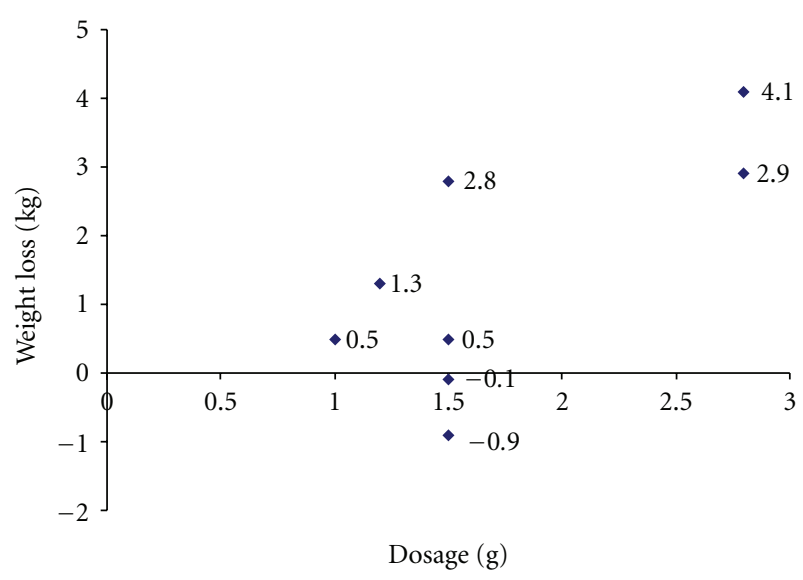

Figure 4: Effect of dosage of HCA on body weight. The dosages from included RCTs did not produce a linear effect on body weight.

Though one of these studies claimed the bioavailability of the HCA used in their trial was high [25], the dosage of HCA used was almost twice that used in the other trial [29]. It is not clear if the higher HCA dosage ensures a higher bioavailability of HCA. A nonlinear, significant $(P<.05)$ correlation between the dosage of HCA and body weight loss seems to exist (Figure 4). Garcinia cambogia was the main source of HCA in most studies, with Garcinia atroviridis being the source of HCA in one included study [2]. None of the trials used Garcinia indica as an intervention. It is unclear if the strain of Garcinia species influences the bioavailability of HCA. Furthermore HCA is also reported to be found in Hibiscus subdariffa [8], and none of the studies included in this review used HCA extracted from this plant species. The duration of the studies included in the review also differed, with a range of 2 to 12 weeks, and mode of 8 weeks. This is probably too short a time to assess the effects of HCA on body weight.

There was some variation in the design of the RCTs included in the review. All of the studies included had parallel-study designs except two which were crossover trials $[26,27]$. Four included RCTs comprised three intervention groups $[6,26,27,29]$. None of the included studies indicated whether or not outcome assessors were blinded, and seven studies did not specify the source of funding $[2,4,6,24,28$, $29,31]$. The failure of study investigators to adhere strictly to the CONSORT guidelines $[10,11]$ may have contributed to the variation in methodology (and heterogeneity) of the trials included in the review.

Most (7/12) RCTs reported adverse events, with headache, nausea, upper respiratory, and gastrointestinal tract symptoms being the most frequent ones. In most of the trials, there were no significant differences in adverse events between HCA and placebo. This seems to corroborate the report in another article [34] which suggested that HCA is safe for human consumption. A few of the studies reported a positive effect of HCA on the blood lipid profile [6, 24, 2931 ], while one did not find any significant difference between HCA and placebo on this blood parameter [2]. However, given the short duration of the studies involving the use of HCA, it is unclear how safe this dietary supplement is on the intermediate and long term. In 2009, the Food and Drug Administration (FDA) warned consumers about the potential for serious adverse effects associated with the consumption of hydroxycut, a popular HCA-containing slimming pill. This resulted in the withdrawal of this supplement from the market [35].

All of the studies included in this review except two $[26,27]$ incorporated some form of dietary control into their trials, with participants in one study receiving high fibre diets [25]. The daily caloric intake for participants in the trials included in this review ranged from as low as $1,000 \mathrm{kcal}$ $[2,30]$, to as high as $3,009 \mathrm{kcal}$ [27]. Half the number of studies in this review did not institute any form of exercise. The extent to which the variation in these lifestyle adjustment factors could have influenced study results is uncertain. Two studies $[28,31]$ reported a significant reduction in appetite in the HCA group $(P<.001)$, but not with placebo. Three other studies did not find any significant difference between HCA and placebo groups in terms of satiety effect $[5,26,27]$.

All of the studies described their participants as overweight, obese, or both. However, in one RCT [2], the definition of the participants as obese individuals is questionable, because they had a BMI between $25-30 \mathrm{~kg} / \mathrm{m}^{2}$. Based on the World Health Organisation definition [36], a BMI between $25-29 \mathrm{~kg} / \mathrm{m}^{2}$ is considered overweight, while a $\mathrm{BMI} \geq 30 \mathrm{~kg} / \mathrm{m}^{2}$ is termed obese.

This systematic review has several limitations. Though our search strategy involved both electronic and nonelectronic studies, we may not have identified all the available trials involving the use of HCA as a weight loss supplement. Furthermore, the methodological quality of most of the studies identified from our searches is poor, and most studies are of short duration. These factors prevent us from drawing firm conclusions about the effects of HCA on body weight.

\section{Conclusion}

The evidence from RCTs suggests that Garcinia extracts/HCA generate weight loss on the short term. However, the magnitude of this effect is small, is no longer statistically significant when only rigorous RCTs are considered, and its clinical relevance seems questionable. Future trials should be more rigorous, longer in duration, and better reported.

\section{Conflict of Interests}

I. Onakpoya was funded by a grant from GlaxoSmithKline. The funder had no role in the preparation of the paper. S. K. Hung, R. Perry, B. Wider and E. Ernest declare no potential competing interests.

\section{Acknowledgment}

The authors would like to thank Ms. Shoko Masuyama for help with translating Japanese articles. 


\section{References}

[1] T. Farhat, R. J. Iannotti, and B. G. Simons-Morton, "Overweight, obesity, youth and health-risk behaviours," American Journal of Preventive Medicine, vol. 38, no. 3, pp. 258-267, 2010.

[2] C. Roongpisuthipong, R. Kantawan, and W. Roongpisuthipong, "Reduction of adipose tissue and body weight: effect of water soluble calcium hydroxycitrate in Garcinia atroviridis on the short term treatment of obese women in Thailand," Asia Pacific Journal of Clinical Nutrition, vol. 16, no. 1, pp. 25-29, 2007.

[3] B. W. Downs, M. Bagchi, G. V. Subbaraju, M. A. Shara, H. G. Preuss, and D. Bagchi, "Bioefficacy of a novel calciumpotassium salt of (-)-hydroxycitric acid," Mutation Research, vol. 579, no. 1-2, pp. 149-162, 2005.

[4] K. Hayamizu, Y. Ishii, I. Kaneko et al., "Effects of Garcinia cambogia (Hydroxycitric Acid) on visceral fat accumulation: a double-blind, randomized, placebo-controlled trial," Current Therapeutic Research, vol. 64, no. 8, pp. 551-567, 2003.

[5] R. D. Mattes and L. Bormann, "Effects of (-)-hydroxycitric acid on appetitive variables," Physiology and Behavior, vol. 71, no. 1-2, pp. 87-94, 2000.

[6] H. G. Preuss, D. Bagchi, M. Bagchi, C. V. S. Rao, S. Satyanarayana, and D. K. Dey, "Efficacy of a novel, natural extract of (-)-hydroxycitric acid (HCA-SX) and a combination of HCA-SX, niacin-bound chromium and Gymnema sylvestre extract in weight management in human volunteers: a pilot study," Nutrition Research, vol. 24, no. 1, pp. 45-58, 2004.

[7] E. Toromanyan, G. Aslanyan, E. Amroyan, E. Gabrielyan, and A. Panossian, "Efficacy of Slim $339^{\circledR}$ in reducing body weight of overweight and obese human subjects," Phytotherapy Research, vol. 21, no. 12, pp. 1177-1181, 2007.

[8] T. Yamada, H. Hida, and Y. Yamada, "Chemistry, physiological properties, and microbial production of hydroxycitric acid," Applied Microbiology and Biotechnology, vol. 75, no. 5, pp. 977982, 2007.

[9] M. Leonhardt, B. Hrupka, and W. Langhans, "Effect of hydroxycitrate on food intake and body weight regain after a period of restrictive feeding in male rats," Physiology and Behavior, vol. 74, no. 1-2, pp. 191-196, 2001.

[10] D. Moher, K. F. Schulz, D. G. Altman, and L. Lepage, "The CONSORT statement: revised recommendations for improving the quality of reports of parallel-group randomised trials," Lancet, vol. 357, no. 9263, pp. 1191-1194, 2001.

[11] D. G. Altman, K. F. Schulz, D. Moher et al., "The revised CONSORT statement for reporting randomized trials: explanation and elaboration," Annals of Internal Medicine, vol. 134, no. 8, pp. 663-694, 2001.

[12] A. R. Jadad, R. A. Moore, D. Carroll et al., "Assessing the quality of reports of randomized clinical trials: is blinding necessary?" Controlled Clinical Trials, vol. 17, no. 1, pp. 1-12, 1996.

[13] Review Manager (RevMan), [Computer Program]. Version 5.0. Copenhagen: The Nordic Cochrane Centre, The Cochrane Collaboration, 2008.

[14] A. A. Conte, "A non-prescription alternative in weight reduction therapy," American Journal of Bariatric Medicine Summer, pp. 17-19, 1993.

[15] M. Girola, M. De Bernardi, and S. Contos, "Dose effect in lipid-lowering activity of a new dietary integrator (Chitosan, Garcinia cambogia extract, and Chrome)," Acta Toxicologica et Therapeutica, vol. 17, pp. 25-40, 1996.
[16] D. Q. Rothacker and B. E. Waitman, "Effectiveness of a Garcinia cambogia and natural caffeine combination in weight loss: a double-blind placebo-controlled pilot study," International Journal of Obesity, vol. 12, supplement 2, p. 53, 1997.

[17] C. A. R. Vasques, S. Rossetto, G. Halmenschlager et al., "Evaluation of the pharmacotherapeutic efficacy of Garcinia cambogia plus amorphophallus konjac for the treatment of obesity," Phytotherapy Research, vol. 22, no. 9, pp. 1135-1140, 2008.

[18] Y. Yonei, Y. Takahashi, S. Hibino, M. Watanabe, and T. Yoshioka, "Effects on the human body of a dietary supplement containing L-carnitine and Garcinia cambogia extract: a study using double-blind tests," Journal of Clinical Biochemistry and Nutrition, vol. 42, no. 2, pp. 89-103, 2008.

[19] V. Badmaev and M. Majeed, "Open field, physician controlled, clinical evaluation of botanical weight loss formula Citrin," in Proceedings of the Nutracon: Nutraceuticals, Dietary Supplements and Functional Foods, Las Vegas, Nev, USA, July 1995.

[20] M. S. Westerterp-Plantenga and E. M. R. Kovacs, "The effect of (-)-hydroxycitrate on energy intake and satiety in overweight humans," International Journal of Obesity, vol. 26, no. 6, pp. 870-872, 2002.

[21] A. A. Conte, "The effects of (-)-hydroxycitrate and chromium (GTF) on obesity," Journal of American College of Nutrition, vol. 13, p. 535, 1994.

[22] H. G. Preuss, R. I. Garis, J. D. Bramble et al., "Efficacy of a novel calcium/potassium salt of (-)-hydroxycitric acid in weight control," International Journal of Clinical Pharmacology Research, vol. 25, no. 3, pp. 133-144, 2005.

[23] E. M. R. Kovacs and M. S. Westerterp-Plantenga, "Effects of (-)-hydroxycitrate on net fat synthesis as de novo lipogenesis," Physiology and Behavior, vol. 88, no. 4-5, pp. 371-381, 2006.

[24] K. Hayamizu, Y. Ishii, and I. Kaneko, "Effects of long-term administration of Garcinia cambogia extract on visceral fat accummulation in humans: a placebo-controlled double blind trial," Journal of Oleo Science, vol. 50, no. 10, pp. 43-50, 2001.

[25] S. B. Heymsfield, D. B. Allison, J. R. Vasselli, A. Pietrobelli, D. Greenfield, and C. Nunez, "Garcinia cambogia (hydroxycitric acid) as a potential antiobesity agent: a randomized controlled trial," Journal of the American Medical Association, vol. 280, no. 18, pp. 1596-1600, 1998.

[26] E. M. R. Kovacs, M. S. Westerterp-Plantenga, M. De Vries, F. Brouns, and W. H. M. Saris, "Effects of 2-week ingestion of (-)-hydroxycitrate and (-)-hydroxycitrate combined with medium-chain triglycerides on satiety and food intake," Physiology and Behavior, vol. 74, no. 4-5, pp. 543-549, 2001.

[27] E. M. R. Kovacs, M. S. Westerterp-Plantenga, and W. H. M. Saris, "The effects of 2-week ingestion of (-)-hydroxycitrate and (-)-hydroxycitrate combined with medium-chain triglycerides on satiety, fat oxidation, energy expenditure and body weight," International Journal of Obesity, vol. 25, no. 7, pp. 1087-1094, 2001.

[28] H. G. Preuss, D. Bagchi, C. V. S. Rao, S. Satyanarayana, and M. Bagchi, "Effect of hydroxycitric acid on weight loss, body mass index and plasma leptin levels in human subjects," FASEB Journal, vol. 16, no. 5, p. A1020, 2002.

[29] H. G. Preuss, D. Bagchi, M. Bagchi, C. V. S. Rao, D. K. Dey, and S. Satyanarayana, "Effects of a natural extract of (-)hydroxycitric acid (HCA-SX) and a combination of HCA-SX plus niacin-bound chromium and Gymnema sylvestre extract on weight loss," Diabetes, Obesity and Metabolism, vol. 6, no. 3, pp. 171-180, 2004. 
[30] R. Roman Ramos, J. Flores Saenz, and M. C. F. Alarcon Aguilar en, "Control of obesity with Garcinia cambogia extract," Investigacion Medica Internacional, vol. 22, no. 3, pp. 97-100, 1996.

[31] E. Thom, "Hydroxycitrate (HCA) in the treatment of obesity," American Journal of Clinical Nutrition, vol. 20, no. 14, p. 48, 1996.

[32] M. H. Pittler and E. Ernst, "Dietary supplements for bodyweight reduction: a systematic review," American Journal of Clinical Nutrition, vol. 79, no. 4, pp. 529-536, 2004.

[33] D. Rucker, R. Padwal, S. K. Li, C. Curioni, and D. C. W. Lau, "Long term pharmacotherapy for obesity and overweight: updated meta-analysis," British Medical Journal, vol. 335, no. 7631, pp. 1194-1199, 2007.

[34] M. G. Soni, G. A. Burdock, H. G. Preuss, S. J. Stohs, S. E. Ohia, and D. Bagchi, "Safety assessment of (-)-hydroxycitric acid and Super CitriMax ${ }^{\circledR}$, a novel calcium/potassium salt," Food and Chemical Toxicology, vol. 42, no. 9, pp. 1513-1529, 2004.

[35] "How Worrisome is the Hydroxycut Recall for the Diet Supplement Industry?" to appear in Nutrition Business Journal, 2009, http://www.nutritionbusinessjournal.com/supplements/news/0505.

[36] World Health Organisation, "Obesity and overweight," Fact sheet no. 311, September 2006, http://www.who.int/mediacentre/factsheets/fs311/en/index.html. 


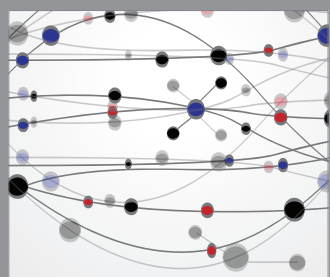

The Scientific World Journal
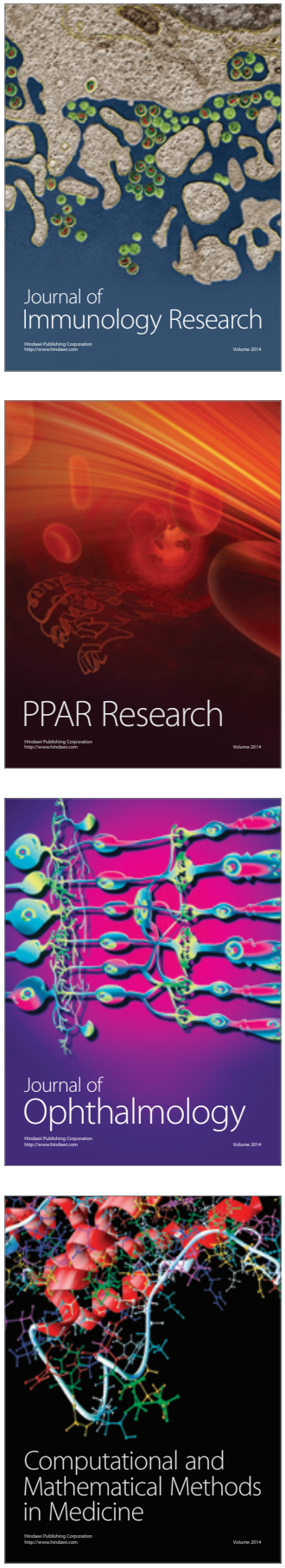

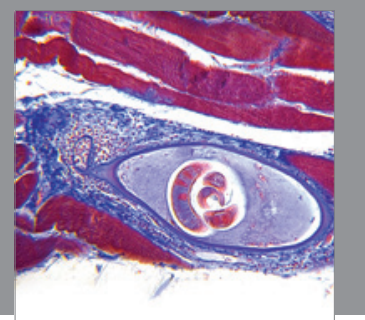

Gastroenterology

Research and Practice
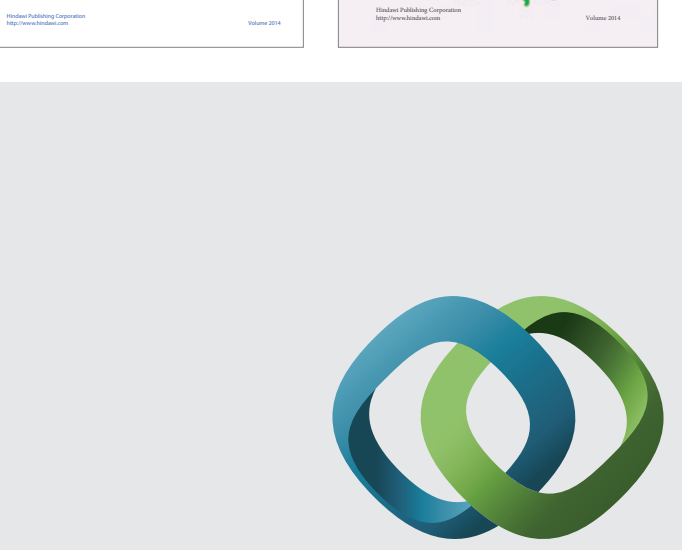

\section{Hindawi}

Submit your manuscripts at

http://www.hindawi.com
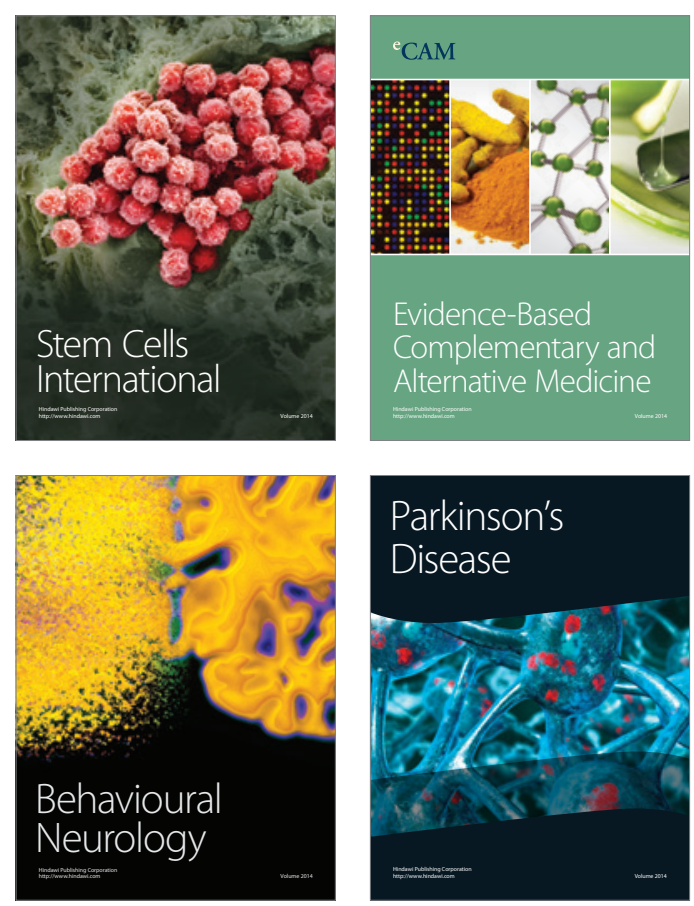

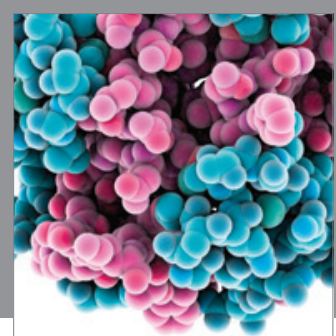

Journal of
Diabetes Research

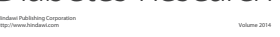

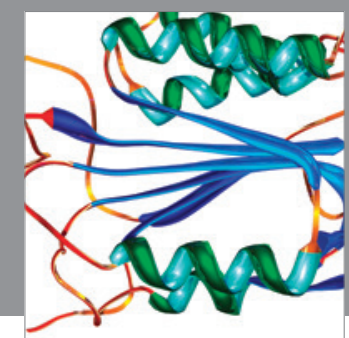

Disease Markers
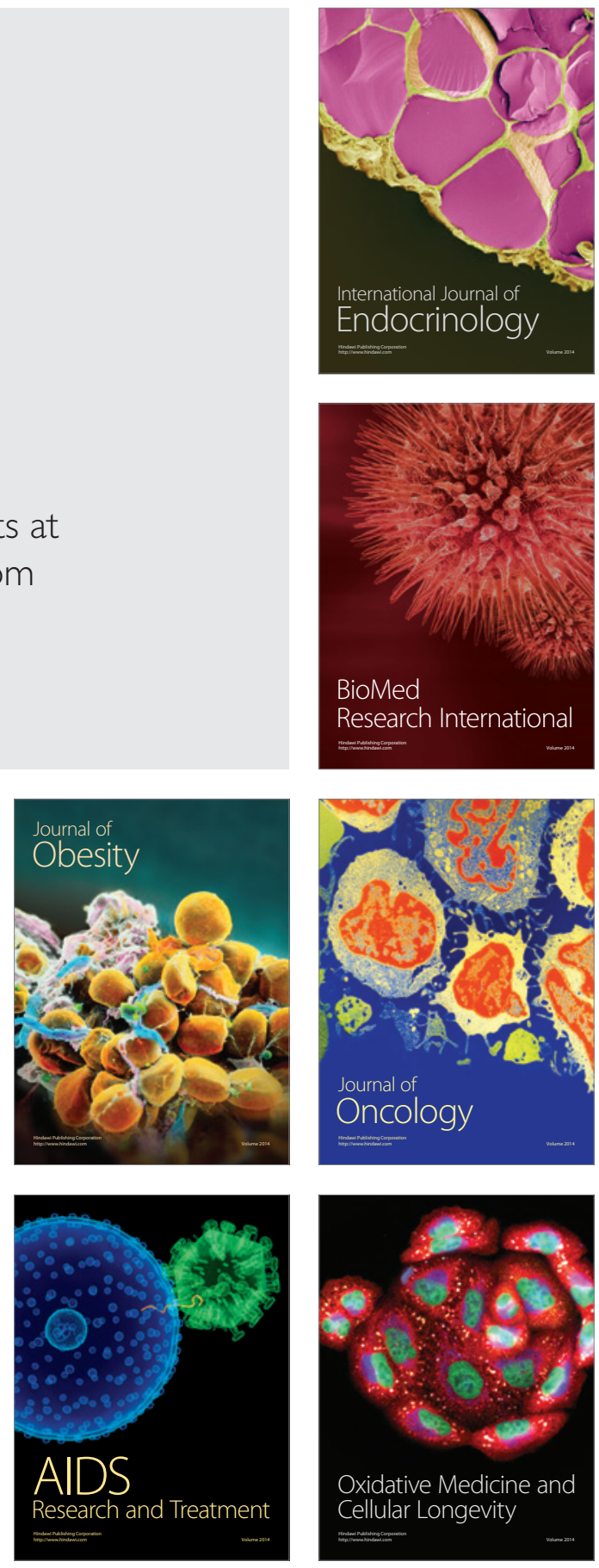